\title{
SYNTHESIS, CHARACTERIZATION AND PHOTO BEHAVIOR OF NEW POLY(AMIDE-IMIDE)/MONTMORILLONITE NANOCOMPOSITE CONTAINING N,N'-PYRROMELLITOYL-BIS-L-ALANINE
}

\author{
Khalil Faghihi $^{{ }^{*}}$, Maryam Rakhshan ${ }^{2}$ and Mohsen Hajibeygi ${ }^{3}$ \\ ${ }^{1}$ Department of Chemistry, Faculty of Science, Arak University, Arak, 38156-8-8349, Iran \\ ${ }^{2}$ Department of Chemistry,Arak Branch, Islamic Azad University, Arak, Iran \\ ${ }^{3}$ Department of Chemistry, Varamin Pishva Branch, Islamic Azad University, Varamin, Iran
}

(Received December 24, 2012; revised June 30, 2013)

\begin{abstract}
Two new samples of poly(amide-imide)-nanocomposites were synthesized by insertion nano silicate particles in poly(amide-imide) (PAI) chains using a convenient solution intercalation technique. PAI as a source of polymer matrix was synthesized by the direct polycondensation reaction of N,N'-pyrromelitoyl-bis-Lalanine with 4,4'-diamino diphenyl ether in the presence of triphenyl phosphite (TPP), $\mathrm{CaCl}_{2}$, pyridine and $\mathrm{N}$ methyl-2-pyrrolidone (NMP). Morphology and structure of the resulting PAI-nanocomposite films with 5 and $10 \%$ silicate particles were characterized by FTIR spectroscopy, X-ray diffraction (XRD) and scanning electron microscopy (SEM). The effect of clay dispersion and the interaction between clay and polymeric chains on the properties of nanocomposites films were investigated by using UV-Vis spectroscopy, thermogravimetric analysis
\end{abstract} (TGA) and water uptake measurements.

KEY WORDS: Nanocomposite, Poly(amide-imide), Silicate particle, Polycondensation, Thermal behavior

\section{INTRODUCTION}

Polymer-clay nanocomposites typically exhibited good mechanical, thermal and gas barrier properties, which are superior to those of the corresponding pure polymers [1-9]. Unique properties of the nanocomposites are usually observed when the ultra fine silicate layers are homogenously dispersed throughout the polymer matrix at nanoscale. The uniform dispersion of silicate layers is usually desirable for maximum reinforcement of the materials. Due to the incompatibility of hydrophilic layered silicates and hydrophobic polymer matrix, the individual nanolayers are not easily separated and dispersed in many polymers. For this purpose, silicate layers are usually modified with an intercalating agent to obtain organically modified clay prior to use in nanocomposite formation [10-11]. Also thermally stable polyamides (PA)s have received much attention over the past decade, owing to increasing demands for highperformance polymers materials for several applications such as high strength, high-modulus fibers, high-temperature coating and high-efficiency semi-permeable membranes. But, due to their low solubility, their applications have been restricted [12-16]. Much effort has been made to create structurally modified aromatic polyamides having better characterization in terms of both solubility and processability with retention of their high thermal stability. Thus, to overcome these processing problems various approaches have been carried out by incorporating flexible units such as $-\mathrm{NHCO}-,-\mathrm{O}-, \mathrm{N}=\mathrm{N}$ and $-\mathrm{SO}_{2}$, and some of which are commercialized. On the other hand introduction of flexible chains into the PAs backbone, the use of metaoriented monomers and synthesis of PAs with non-coplanar unit in the polymer chains, resulted in a number of modified PAs. Another strategy is based on the introduction of bulky side groups into the polymer chains [17-24].

\footnotetext{
*Corresponding author. E-mail: k-faghihi@araku.ac.ir
} 
In this article two PAI-nanocomposite films with 5 and $10 \%$ silicate particles containing $\mathrm{N}, \mathrm{N}$-pyrromelitoyl-bis-L-alanine moiety in the main chain were prepared by using a convenient solution intercalation technique.

\section{EXPERIMENTAL}

\section{Materials}

Pyrromellitic anhydride, L-alanine, 4,4'-diamino diphenyl ether, acetic acid, triphenyl phosphite (TPP), $\mathrm{CaCl}_{2}$, pyridine and $\mathrm{N}$-methyl-2-pyrrolidone (NMP) were purchased from Merck Chemical Company and used without further purification. Purified organically modified Cloisite 20A supplied by Southern Clay Products (TX, USA) was used as polymer nanoreinforcement.

\section{Techniques}

${ }^{1} \mathrm{H}-\mathrm{NMR}$ spectrum was recorded on a Bruker $300 \mathrm{MHz}$ instrument (Germany). Fourier transform infrared (FTIR) spectra were recorded on Galaxy Series FTIR 5000 spectrophotometer (England). UV-visible spectra were recorded at $25^{\circ} \mathrm{C}$ in the $250-700 \mathrm{~nm}$ spectral regions with a Perkin Elmer Lambda 15 spectrophotometer in NMP solution using cell lengths of $1.0 \mathrm{~cm}$. Thermal gravimetric analysis (TGA and DTG) data were taken on a Mettler TA4000 System under $\mathrm{N}_{2}$ atmosphere at a rate of $10{ }^{\circ} \mathrm{C} / \mathrm{min}$. The morphology and structure of nanocomposite film were investigated on Cambridge S260 scanning electron microscope (SEM). X-ray diffraction (XRD) were performed on Philips X-Pert $(\mathrm{Cu}-\mathrm{Ka}$ radiation, $\lambda=$ $0.15405 \mathrm{~nm}$ ). The water absorption of PAI-nanocomposite films were carried out using a procedure under ASTM D570-81 [25].

Monomer synthesis

$\mathrm{N}, \mathrm{N}$-pyrromelitoyl-bis-L-alanine $\mathbf{1}$ was prepared according to a typical procedure [23].

Polymer synthesis

Into a $100 \mathrm{~mL}$ round bottomed flask were placed a mixture of $\mathrm{N}, \mathrm{N}$-pyrromelitoyl-bis-L-alanine 1 (0.002 mol), 4,4'-diamino diphenyl ether $2(0.002 \mathrm{~mol}), 0.60 \mathrm{~g}$ of calcium chloride, $1.0 \mathrm{~mL}$ of triphenyl phosphite, $1.0 \mathrm{~mL}$ of pyridine and $4.0 \mathrm{~mL}$ NMP. The mixture was heated for $1 \mathrm{~h}$ at 60 ${ }^{\circ} \mathrm{C}, 2 \mathrm{~h}$ at $90{ }^{\circ} \mathrm{C}$ and then refluxed at $140{ }^{\circ} \mathrm{C}$ for $8 \mathrm{~h}$ until a viscous solution was formed. Then it was cooled to room temperature and $30 \mathrm{~mL}$ of methanol was added to reaction mixture. The precipitate was formed, filtered off and washed with methanol. The resulting poly(amide-imide) 3 was dried under vacuum. The inherent viscosity of this soluble PAI 3 was $0.55 \mathrm{dL} / \mathrm{g}$. Elemental analysis $(\mathrm{CHN})$ for $\mathrm{C}_{28} \mathrm{H}_{20} \mathrm{~N}_{4} \mathrm{O}_{7}$ : calculated: $\mathrm{C}, 64.12 ; \mathrm{H}, 3.84 ; \mathrm{N}, 10.68$. Found: $\mathrm{C}$, 63.04; H, 3.77; N, 10.61 .

\section{PAI-Nanocomposite synthesis $\mathbf{4 a}$ and $\mathbf{4 b}$}

PAI-nanocomposites $\mathbf{4 a}$ and $\mathbf{4 b}$ were produced by solution intercalation method. Two different amounts of organoclay particles (5 and 10 -wt.\%) were mixed with appropriate amounts of PAI solution in N-methyl-2-pyrrolidone (NMP) to yield particular nanocomposite concentrations. To control the dispersibility of organoclay in polyamide matrix, constant stirring was applied at 25 ${ }^{\circ} \mathrm{C}$ for $24 \mathrm{~h}$. Nanocomposite films were cast by pouring the solutions for each concentration into petri dishes placed on a levelled surface followed by the evaporation of solvent at $70{ }^{\circ} \mathrm{C}$ for 12 h. Films were dried at $80{ }^{\circ} \mathrm{C}$ under vacuum to a constant weight. 
The water absorption analysis

The water absorption of PAI-nanocomposite films was carried out using a procedure under ASTM D570-81 [25]. The films were dried in a vacuum oven at $80{ }^{\circ} \mathrm{C}$ to a constant weight and then weighed to get the initial weight $\left(\mathrm{W}_{\mathrm{o}}\right)$. The dried films were immersed in deionized water at $25{ }^{\circ} \mathrm{C}$. After $24 \mathrm{~h}$, the films were removed from water and then they were quickly placed between sheets of filter paper to remove the excess water and films were weighed immediately. The films were again soaked in water. After another $24 \mathrm{~h}$ soaking period, the films were taken out, dried and weighed for any weight gain. This process was repeated again and again till the films almost attained the constant weight. The total soaking time was $168 \mathrm{~h}$ and the samples were weighed at regular $24 \mathrm{~h}$ time intervals to get the final weight $\left(\mathrm{W}_{\mathrm{f}}\right)$. The percent increase in weight of the samples was calculated by using the formula $\left(\mathrm{W}_{\mathrm{f}}-\mathrm{W}_{\mathrm{o}}\right) / \mathrm{W}_{\mathrm{o}}$.

\section{RESULTS AND DISCUSSION}

\section{Monomer synthesis}

N,N'-pyrromelitoyl-bis-L-alanine $\mathbf{1}$ was synthesized from one equimolar pyrromellitic anhydride and two equimolar of L-alanine in acetic acid [23].

\section{Polymer synthesis}

Poly(amide-imide) $\mathbf{3}$ was synthesized by the direct polycondensation reaction of an equimolar mixture of diacid 1, an equimolar mixture of diamine $\mathbf{2}$ by using triphenyl phosphite (TPP) and pyridine as condensing agents (Scheme 1).

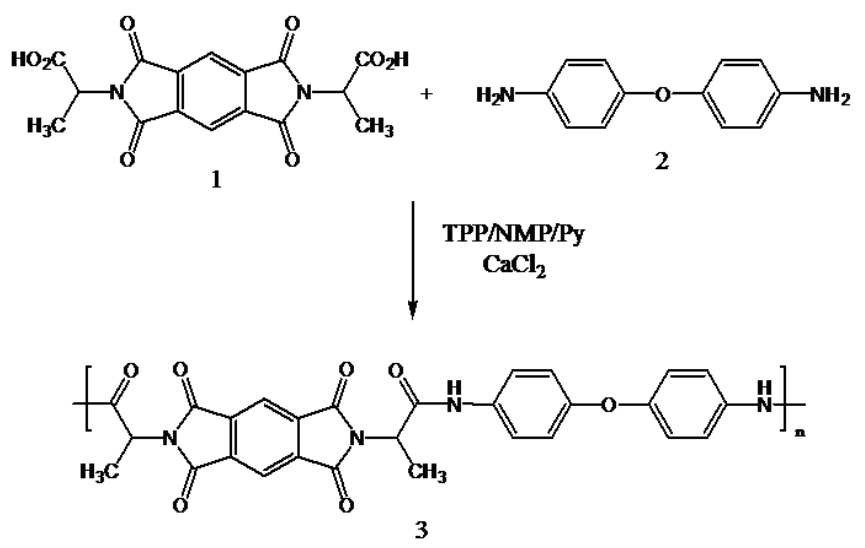

Scheme 1. Synthetic route of PAI 3.

PAI 3 was obtained in good yield (99\%) and inherent viscosity $0.55 \mathrm{dLg}^{-1}$. The structure of resulting polymer 3 was confirmed as PAI by using FTIR spectroscopy and elemental analyses. The resulting polymer have absorption band at $1680 \mathrm{~cm}^{-1}$ due to amide carbonyl groups. Absorption bands at $3300 \mathrm{~cm}^{-1}$ demonstrated the presence of the amide $\mathrm{N}-\mathrm{H}$ stretching absorption in this polymer (Figure 1). The elemental analysis value of the resulting polymer was in good agreement with the calculated values for the proposed structure. 


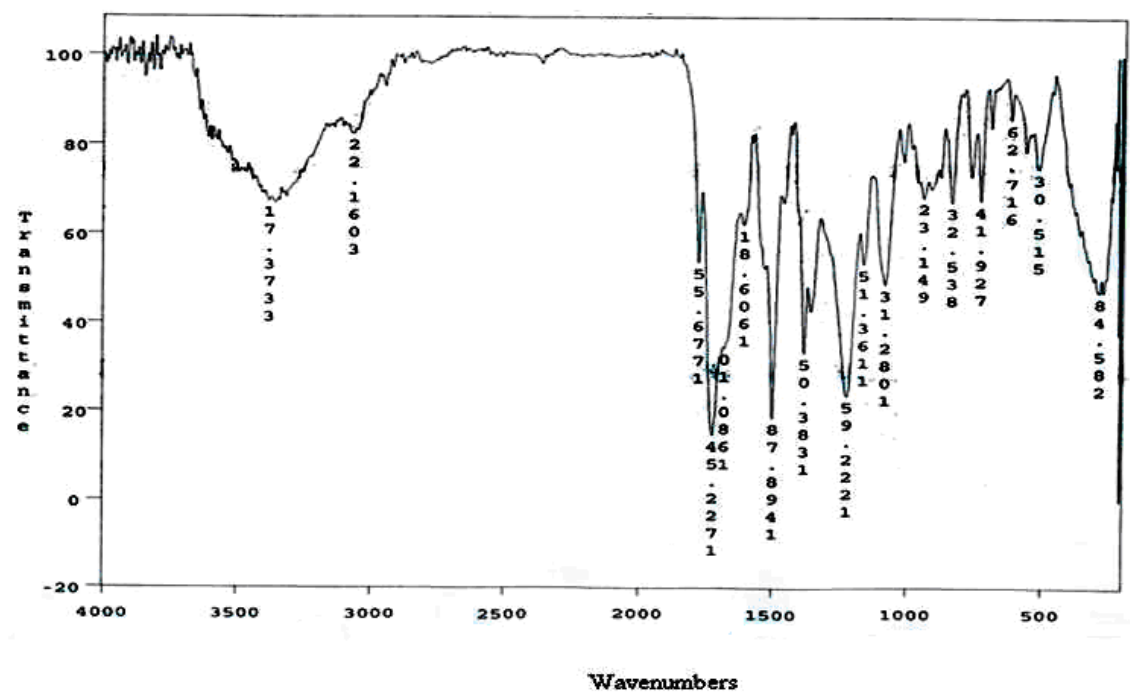

Figure 1. FTIR spectrum of PAI 3.

\section{PAI-nanocomposite films}

Scheme 2 shows the flow sheet diagram and synthetic scheme for PAI-nanocomposites film 4a and $\mathbf{4 b}$.

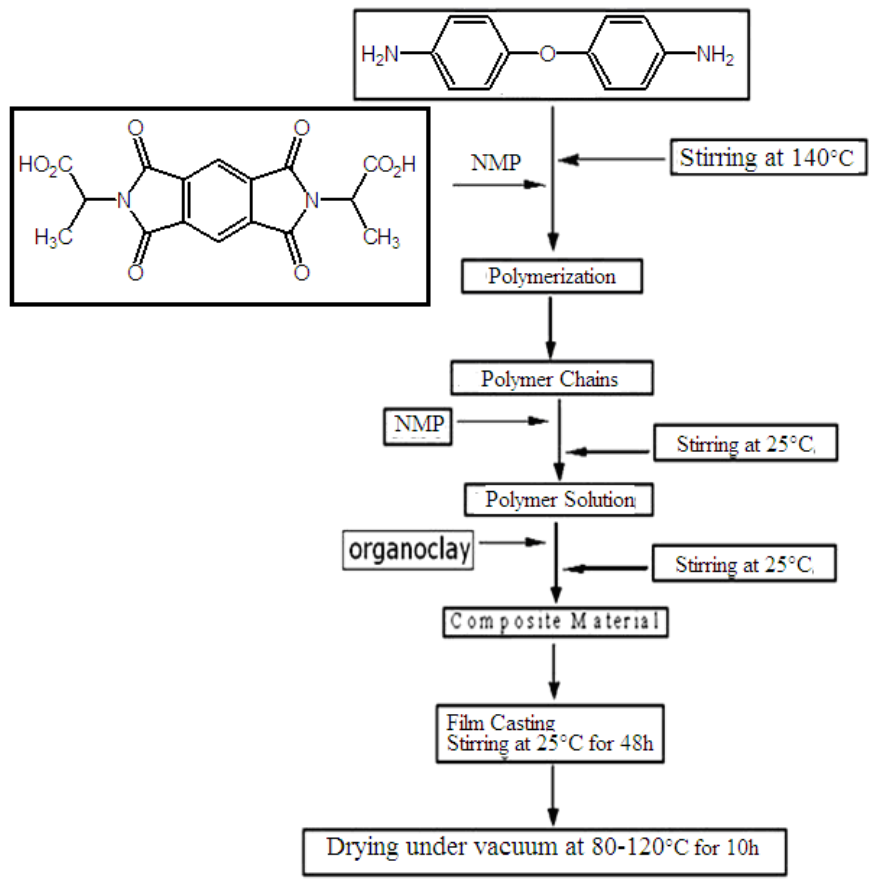

Scheme 2. Flow sheet diagram for the synthesis of PAI-nanocomposites film $\mathbf{4 a}$ and $\mathbf{4 b}$.

Bull. Chem. Soc. Ethiop. 2013, 27(3) 
FT-IR spectroscopy analyses

FT-IR spectrum of PAI-nanocomposite films $\mathbf{4 a}$ and $\mathbf{4 b}$ showed the characteristic absorption bands of the $\mathrm{Si}-\mathrm{O}$ and $\mathrm{Mg}-\mathrm{O}$ moieties at 1076,513 and $466 \mathrm{~cm}^{-1}$, respectively. The incorporation of organic groups in PAI-nanocomposite films was confirmed by the presence of peaks at 3292 and 1664 (amide N-H stretching and carbonyl group) (Figure 2).

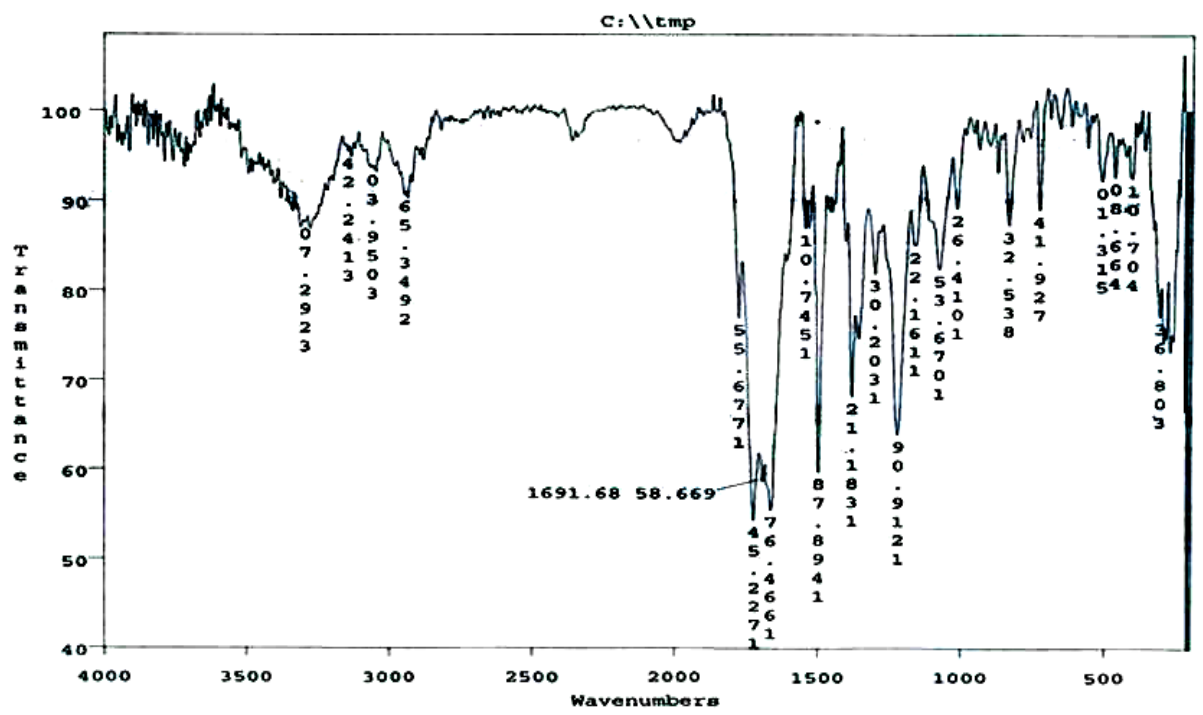

Figure 2. FTIR spectrum of PAI-nanocomposite films $\mathbf{4 a}$.

\section{$X$-ray diffraction analysis}

Figure 3 shows the XRD patterns of PAI-nanocomposite films $\mathbf{4 a}$ and $\mathbf{4 b}$ containing 5 and 10wt.\% of silicate particles. These results indicated significant expansion of the silicate layer after insertion PAI chains. The shift in the diffraction peaks PAI-nanocomposite films confirms that intercalation has been taken place. This is direct evidence that PAI-nanocomposites have been formed as the nature of intercalating agent also affects the organoclay dispersion in the polymer matrix. Usually there are two types of nanocomposites depending upon the dispersion of clay particles. The first type is an intercalated polymer clay nanocomposite, which consists of well ordered multi layers of polymer chain and silicate layers a few nanometers thick. The second type is an exfoliated polymer-clay nanocomposite, in which is there is a loss of ordered structures due to the extensive penetration of polymer chain into the layer silicate. Such part would not produce distinct peaks in the XRD pattern [27]. In our PAI-nanocomposite films there are coherent XRD signal at $5.32^{\circ}$ and $4.46^{\circ}$ related to 5 and $10 \mathrm{wt} . \%$ nanocomposite films, respectively.

\section{Scanning electron microscopy}

The surface morphology of the PAI-nanocomposite films prepared by solution intercalation technique is compared by SEM analyses. Figure 4 shows the morphological images of 5 and 10 wt.\% nanocomposite films, respectively. The SEM images show that PAI matrix has a smooth 
morphology. Also SEM micrographs of PAI-nanocomposite containing 5 and $10 \mathrm{wt} \%$ clay platelets were uniformly distributed without agglomeration.
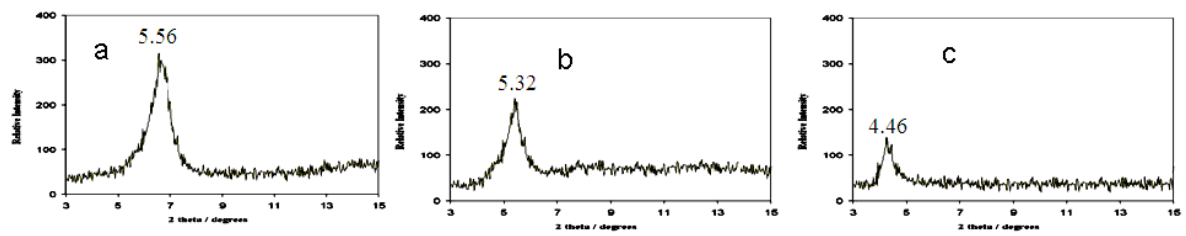

Figure 3. X-ray diffraction patterns of organoclay (a), PAI-nanocomposite films $\mathbf{4 a}$ (b) and $\mathbf{4 b}$ (c).
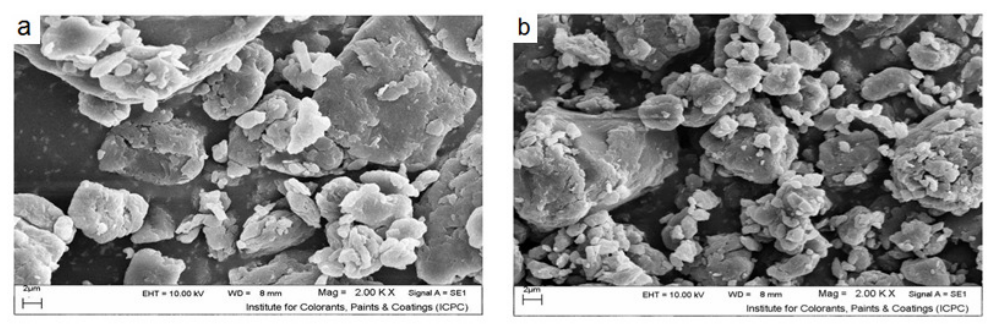

Figure 4. Scanning electron micrographs of PAI-nanocomposite films $\mathbf{4 a}$ (a) and $\mathbf{4 b}$ (b).

Optical clarity of PAI-nanocomposite films

Optical clarity of PAI-nanocomposite films containing 5 and 10 wt.\% clay platelets and neat PAI was compared by UV-Vis spectroscopy in the region of 200-800 $\mathrm{nm}$. Figure 5 shows the UV-Vis transmission spectra of pure PAI and PAI-nanocomposite films containing 5 and 10 wt. \% clay platelets. This spectrum shows the UV-Visible region $(220-500 \mathrm{~nm})$ is affected by the presence of the clay particles and exhibiting low transparency reflected to the primarily intercalated composites. Results shows that the optical clarity of PAI-nanocomposite films system is significantly lower the neat PAI system.

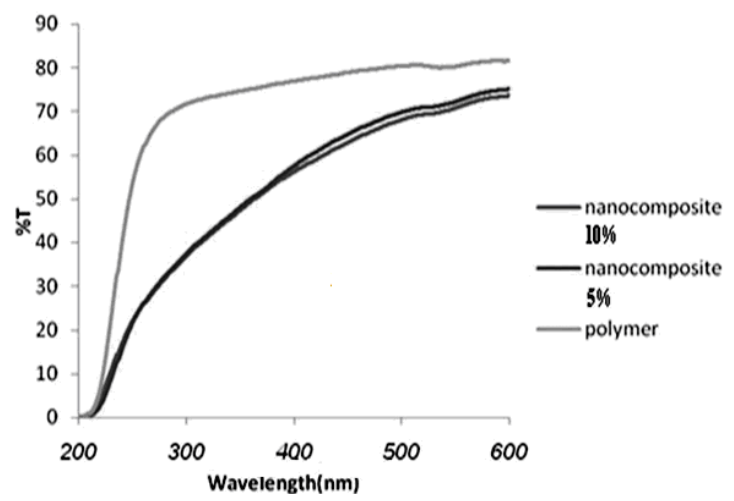

Figure 5. UV-Vis spectra of PAI 3, PAI-nanocomposite films $\mathbf{4 a}$ and $\mathbf{4 b .}$ 


\section{Thermogravimetric analysis}

The thermal properties of PAI-nanocomposite films containing 5 and $10 \mathrm{wt} \%$ clay platelets and neat PAI were investigated by using TGA in nitrogen atmosphere at a rate of heating of 10 ${ }^{\circ} \mathrm{C} / \mathrm{min}$, and thermal data are summarized in Table 1 (Figure 6). These samples exhibited good resistance to thermal decomposition, up to $112{ }^{\circ} \mathrm{C}$ in nitrogen, and began to decompose gradually above this temperature. $\mathrm{T}_{5}$ for these polymers ranged from $112-114{ }^{\circ} \mathrm{C}$ and $\mathrm{T}_{10}$ for them ranged from $136-138{ }^{\circ} \mathrm{C}$, and residual weights at $600{ }^{\circ} \mathrm{C}$ and $800{ }^{\circ} \mathrm{C}$ ranged from 43.85 and $38.73 \%$ in nitrogen, respectively. Incorporation of organoclay into the PAI matrix also enhanced the thermal stability of the nanocomposites. Figure 6 shows the TGA thermograms of PAI-nanocomposites under nitrogen atmosphere. Thus, we can speculate that interacting PAIs chains between the clay layers serve to improve the thermal stability of nanocomposites. The addition of organoclay in polymeric matrix can significantly improve the thermal stability of PAI.

Table 1. Thermal behaviors and water uptake of neat PAI 4 and PAI-nanocomposite films $\mathbf{4 a}$ and $\mathbf{4 b}$.

\begin{tabular}{|c|c|c|c|c|c|}
\hline Polymer & $\mathrm{T}_{5}\left({ }^{\circ} \mathrm{C}\right)^{\mathrm{a}}$ & $\mathrm{T}_{10}\left({ }^{\circ} \mathrm{C}\right)^{\mathrm{b}}$ & Char Yield $^{\mathrm{c}(600)}$ & Char Yield $^{\mathrm{c}(800)}$ & Water uptake (\%) \\
\hline $\mathbf{4}$ & 112 & 136 & 43.85 & 38.73 & 6.1 \\
\hline 4a & 134 & 165 & 49.31 & 44.15 & 1.9 \\
\hline 4b & 215 & 306 & 57.35 & 49.43 & 0 \\
\hline
\end{tabular}

${ }^{\mathrm{a}, \mathrm{b}}$ Temperature at which $5 \%$ and $10 \%$ weight loss was recorded by TGA at heating rate of $10{ }^{\circ} \mathrm{C} / \mathrm{min}$ in $\mathrm{N}_{2}$ respectively ${ }^{\circ}$ Percentage weight of material left undecomposed after TGA analysis $600{ }^{\circ} \mathrm{C}$ and $800{ }^{\circ} \mathrm{C}$.

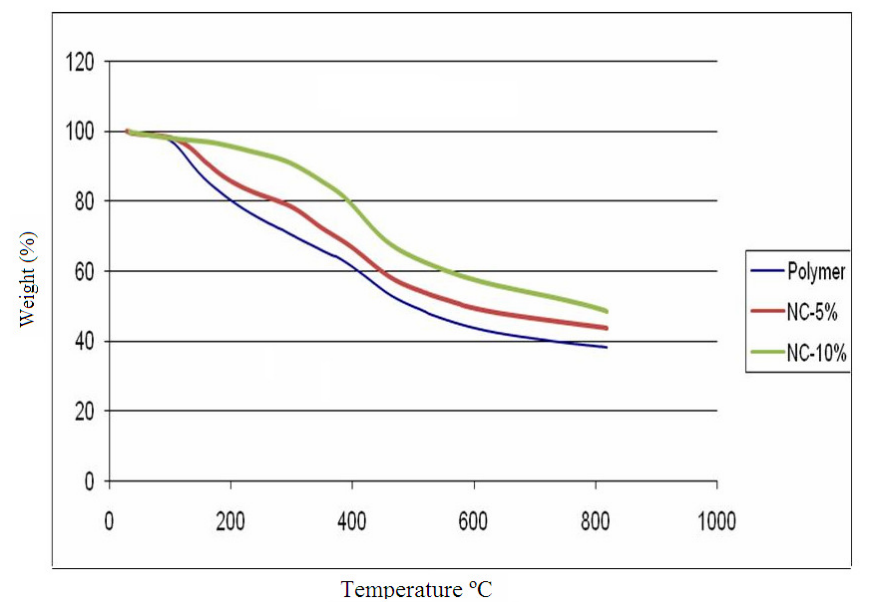

Figure 6. TGA thermograms of neat PAI 3 and PAI-nanocomposite films $\mathbf{4 a}$ and $\mathbf{4 b .}$

\section{Water absorption measurements}

The PAI under investigation contains polar amide groups in the backbone that have the tendency to uptake water through hydrogen bonding. Thus water absorption measurements become necessary for neat PAI 3 and PAI-nanocomposite films $\mathbf{4 a}$ and $\mathbf{4 b}$ and data are shown in Table 1 (Figure 7). In the water permeability studies, we found that the incorporation of clay platelets into PA matrix results in a decrease of water uptake relative to pure PAI by forming the tortuous path of water permeant. Water permeability depends on length, orientation and degree

Bull. Chem. Soc. Ethiop. 2013, 27(3) 
of delamination of layered silicate [25]. It should be noted that a further increase in clay concentration resulted in an enhanced barrier property of nanocomposites which may be attributed to the plate-like clays that effectively increase the length of the diffusion pathways, as well as decrease the water permeability.

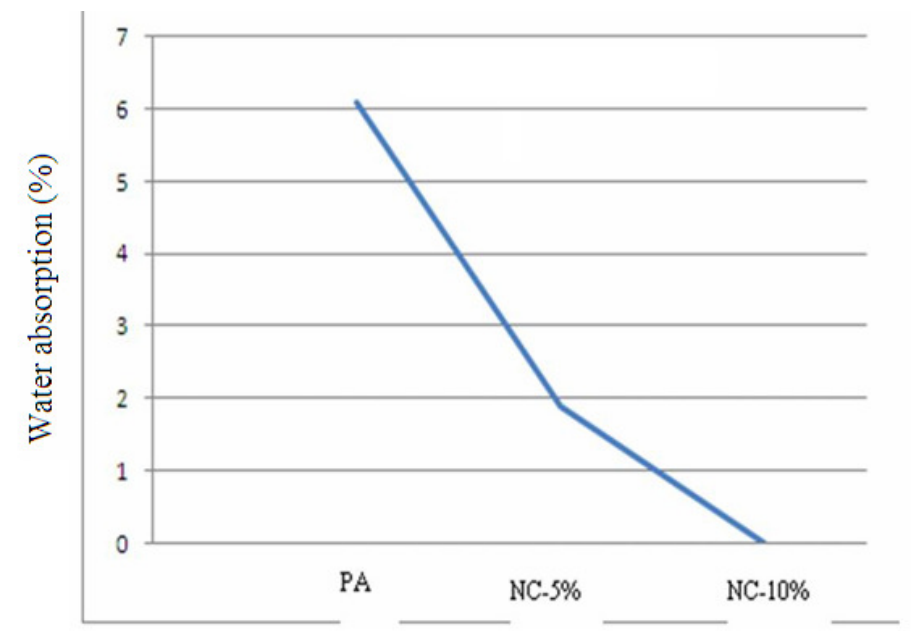

Figure 7. Water absorption measurements become necessary for neat PAI 3 and PAInanocomposite films $\mathbf{4 a}$ and $\mathbf{4 b}$.

\section{CONCLUSIONS}

The PAI-nanocomposites were successfully prepared using solution intercalation method. The structure and the uniform dispersion of organoclay throughout the PAI matrix were confirmed by FTIR, XRD and SEM analyses. The optical clarity and water absorption property of PAInanocomposites were decreased significantly with increasing the organoclay contents in PAI matrix. On the contrary the thermal stability of PAI-nanocomposites was increased significantly with increasing the organoclay contents in PAI matrix. The enhancements in the thermal stability of the nanocomposites films $\mathbf{4 a}$ and $\mathbf{4 b}$ caused by introducing organoclay may be due to the strong interactions between polymeric matrix and organoclay generating well intercalation and dispersion of clay platelets in the PAI matrix.

\section{REFERENCES}

1. Biswas, M.; Ray, S.S. Adv. Polym. Sci. 2001, 155, 167.

2. McNally, T.; Murphy, W.R.; Lew, C.Y.; Turner, R.T.; Brennan, G.P. Polymer 2003, 44, 2761.

3. Shen, L.; Phang, I.Y.; Chen, L.; Liu, T.; Zeng, K. Polymer 2004, 45, 3341.

4. Gain, O.; Espuche, E.; Pollet, E.; Alexandre, M.; Dubois, P. J. Polym. Sci. Part B: Polym. Phys. 2005, 43, 205.

5. Gonzalez, I.; Eguiazabal, J.I.; Nazabal, J.; Exfoliated, P.A. Polymer 2005, 46, 2978.

6. Lopez, D.G.; Mitre, I.G.; Fernandez, J.F.; Merino, J.C.; Pastor, J.M. Polymer 2005, 46, 2758.

7. Nah, C.W.; Ryu, H.J.; Kim, W.D.; Choi, S.S. Polym. Adv. Technol. 2002, 13, 649.

Bull. Chem. Soc. Ethiop. 2013, 27(3) 
8. Huang, J.C.; Zhu, Z.K.; Yin, J.; Qian, X.F.; Sun, Y.Y. Polymer 2001, 42, 873.

9. Hu, Y.; Song, L.; Xu, J.; Yang, L.; Chem, Z.; Fan, W. Colloid. Polym. Sci. 2001, 279, 819.

10. Zulfiqar, S.; Ahmad, Z.; Ishaq, M.; Saeed, S.; Sarwar, M.I. J. Mater. Sci. 2007, 42, 93.

11. Kausar, A.; Zulfiqar, S.; Shabbir, S.; Ishaq, M.; Sarwar, M.I. Polym. Bull. 2007, 59, 457.

12. Mallakpour, S.; Kolahdoozan, M. Iran. Polym. J. 2008, 17, 531.

13. Hsiao, S.H.; Chang, Y.M.; Chen, H.W.; Liou, G.S. J. Polym. Sci. Part A: Polym. Chem. 2006, 44, 4579.

14. Al-Ghamdi, R.F.; Fahmi, M.M.; Mohamed, N.A. Polym. Degrad. Stab. 2006, 91, 1530.

15. Higashi, F.; Yokote, S.; Murakawa, T. J. Polym. Sci. Part A: Polym. Chem. 2004, 42, 4126.

16. Hsiao, S.H.; Chen, C.W.; Liou, G.S. J. Polym. Sci. Part A: Polym. Chem. 2004, 42, 3302.

17. Ayala, V.; Maya, E.M.; Garcia, J.M.; De La Campa, J.G.; Lozano, A.E.; De Abajo, J. J. Polym. Sci. Part A: Polym. Chem. 2005, 43, 112.

18. Mallakpour, S.; Rafiee, Z. Iran. Polym. J. 2008, 17, 907.

19. Faghihi, Kh.; Hajibeygi, M.; Shabanian, M. J. Polym. Res. 2010, 17, 379.

20. Faghihi, Kh.; Hajibeygi, M.; Shabanian, M. Polym. Int. 2010, 59, 218.

21. Faghihi, Kh.; Gholizadeh, M. Macromol. Res. 2010, 18, 2.

22. Faghihi, Kh.; Moghanian, H. Polym. Bull. 2010, 65, 319.

23. Faghihi, Kh.; Hajibeygi, M. Chin. J. Polym. Sci. 2010, 28, 517.

24. Faghihi, Kh.; Hajibeygi, M.; Shabanian, M. J. Macromol. Sci. Part A: Pure Appl. Chem. 2010, 47, 144.

25. Zulfiqar, S.; Sarwar, M.I. J. Incl. Phenom. Macrocycl. Chem. 2008, 62, 353.

26. Faghihi, Kh.; Hagibeygi, M. Eur. Polym. J. 2003, 39, 2307.

27. Bharadwaj, R.K. Macromolecules 2001, 34, 9189. 